\title{
Development of microstructure and texture of medium carbon steel during heavy warm deformation
}

\author{
L. Storojeva *, D. Ponge, R. Kaspar, D. Raabe \\ Max-Planck-Institut für Eisenforschung, Max-Planck-Str.1, Düsseldorf D-40237, Germany
}

Received 2 December 2003; received in revised form 12 January 2004; accepted 13 January 2004

\begin{abstract}
The microstructure and texture development of a medium-carbon steel $(0.36 \% \mathrm{C})$ during heavy warm deformation (HWD) was studied using scanning electron microscopy and electron back scattering diffraction. The spheroidization of pearlite is accelerated due to the HWD, which leads to the formation of completely spheroidized cementite already after the deformation and coiling at 873 $\mathrm{K}\left(600^{\circ} \mathrm{C}\right)$. The homogeneity of the cementite distribution depends on the cooling rate and the coiling temperature. The cooling rate of about $10 \mathrm{~K} / \mathrm{s}$ (ferrite-pearlite prior to HWD) and deformation/coiling at 943-973 $\mathrm{K}\left(670-700{ }^{\circ} \mathrm{C}\right)$ lead to a homogeneous cementite distribution with a cementite particle size of less than $1 \mu \mathrm{m}$. The ferrite softening can be attributed to continuous recrystallization. Even up to fairly high deformation/coiling temperatures of $983 \mathrm{~K}\left(710^{\circ} \mathrm{C}\right)$ the texture consists of typical deformation components. During the continuous recrystallization the amount of high angle grain boundaries can increase up to $70 \%$ with a ferrite grain size of 1-3 $\mu \mathrm{m}$. An increase of the cooling rate up to $20 \mathrm{~K} / \mathrm{s}$ (ferrite-pearlite-bainite prior to HWD) deteriorates the homogeneity of the cementite distribution and the softening of ferrite in the final microstructure.
\end{abstract}

(C) 2004 Acta Materialia Inc. Published by Elsevier Ltd. All rights reserved.

Keywords: Heavy warm deformation; Ferritic-pearlitic steel; Continuous recrystallization; Texture; EBSD

\section{Introduction}

After conventional hot rolling of medium carbon steel, a lamellar pearlite is formed during $\gamma-\alpha$ transformation. The lamellar morphology of pearlite leads to mechanical properties unsuitable for a further cold treatment or for application in highly demanding components. The globular morphology of cementite provides some benefits such as high toughness, good cold formability and machinability. For such purposes the cold strip must either undergo a long annealing treatment to obtain higher cold formability or it must be quenched with a subsequent tempering for a good combination of strength and toughness.

The use of a heavy warm deformation (HWD), performed below the $\gamma-\alpha$ transformation-temperature accelerates essentially the spheroidization of pearlite.

\footnotetext{
${ }^{*}$ Corresponding author. Tel.: +49-211-679-2260; fax: +49-211-6792333.

E-mail address: storojeva@mpie.de (L. Storojeva).
}

The rate of this process is accelerated by a factor of $10^{4}$ compared to annealing without deformation [1,2]. But the spheroidized cementite itself cannot provide good mechanical properties. Other microstructural features like a homogeneous cementite distribution or ferrite condition, as well as the size of the cementite particles or the ferrite grains, influence the final mechanical properties. Therefore, a better understanding of the microstructure evolution during HWD is important for a successful introduction of such processing into the industrial production.

\section{Material and experimental technique}

A ferritic-pearlitic steel with a following composition in mass \% was studied: $0.36 \% \mathrm{C}, 0.53 \% \mathrm{Mn}, 0.22 \% \mathrm{Si}$, $0.011 \% \mathrm{P}$ and $0.002 \% \mathrm{~S}$. The axially symmetric compression of samples with initial size $18 \times 18 \times 30 \mathrm{~mm}^{3}$ and plane strain compression of samples with an initial thickness of $60 \mathrm{~mm}$, width of $50 \mathrm{~mm}$ and length of 45 
$\mathrm{mm}$, cut from an industrial slab, were carried out on the hot deformation simulator of the Max-Planck-Institute [3] with a strain rate of $10 \mathrm{~s}^{-1}$. This servohydraulic press is capable of conducting large-scale thermomechanical processes by performing multi-step hot compression tests as a realistic approximation of industry-scale hot forming operations.

After the austenite deformation (true strain of 0.3 ) at $1173 \mathrm{~K}\left(900^{\circ} \mathrm{C}\right)$, the samples were cooled with various cooling rates between 2 and $20 \mathrm{~K} / \mathrm{s}$ to obtain the $\gamma-\alpha$ transformation. The HWD was carried out at 873-983 $\mathrm{K}\left(600-710^{\circ} \mathrm{C}\right)$ using a multi-pass mode $(4$ passes $\times 0.4$ strain, interpass time around $0.5 \mathrm{~s}$ ) with a subsequent coiling simulation at $873-983 \mathrm{~K}\left(600-710{ }^{\circ} \mathrm{C}\right)$ for $2 \mathrm{~h}$.

The deformation-dilatometry technique was used for the establishment of CCT diagrams after the deformation in austenite. The microstructure investigation was carried out using scanning electron microscopy. The condition of the ferrite was additionally studied by the electron back scattering diffraction (EBSD).

\section{Results and discussion}

\subsection{CCT diagram}

The continuous cooling transformation diagram (Fig. 1) was established after an austenite deformation at $1173 \mathrm{~K}\left(900^{\circ} \mathrm{C}\right)$. This temperature was determined by pre-tests to provide fine recrystallized austenite grains as an initial microstructure before the transformation.

The main differences between the microstructures produced with different cooling rates (initial microstructures for the subsequent HWD) were the amount of proeutectoid ferrite, the presence of bainite and the

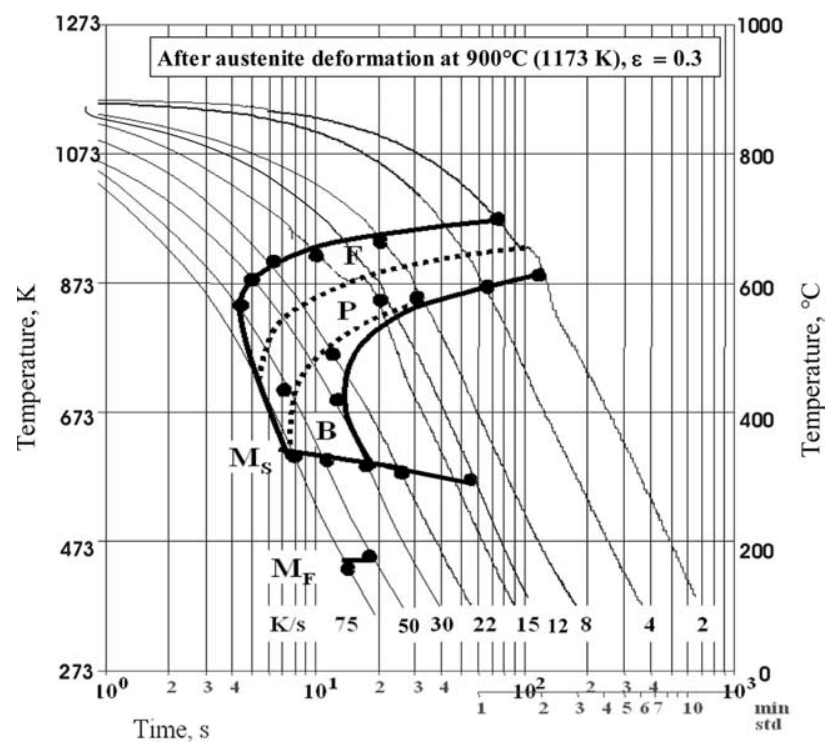

Fig. 1. CCT diagram after austenite deformation. thickness of pearlite lamellae. After slow cooling $(2 \mathrm{~K} / \mathrm{s})$ the microstructure contains coarse lamellar pearlite with a thick network of proeutectoid ferrite. After cooling with a faster cooling rate of $8 \mathrm{~K} / \mathrm{s}$, the ferrite network is thinner and the lamellae are finer. After higher cooling rates $(30 \mathrm{~K} / \mathrm{s})$, the microstructure contains fine lamellar pearlite, bainite and martensite with only a small amount of ferrite.

\subsection{Spheroidization of pearlite}

Pearlite colonies with a different orientation after HWD with subsequent cooling at a low rate, $2 \mathrm{~K} / \mathrm{s}$, and deformation/coiling temperatures of $873 \mathrm{~K}\left(600^{\circ} \mathrm{C}\right)$ are shown in Fig. 2(a) and (b). The formation of spheroidized cementite particles along the former pearlite lamellae can be seen. According to Chattopadhyay and Sellars [4], an excess of vacancies, which formed during the deformation, promotes carbon diffusion, especially near lamellae kinks, which are characteristic of severely deformed pearlite [2,5]. An important factor for the acceleration of the spheroidization process can be a local difference between the equilibrium carbon concentrations in ferrite near the surface of a deformed lamella with different curvature radii, according to the GibbsThompson equation. As reported in [6,7], the equilibrium carbon concentration in ferrite in the vicinity of the lamella with a small curvature radius is higher compared to that of larger one. After a heavy deformation of pearlite the numerous kinks of the lamellae occur with small radii and so with the equilibrium carbon concentration in ferrite near kinks essential higher as compared to that close to the flat parts of lamellae. Together with the high defect density the carbon diffusion leads to a rapid dissolution of lamellae kinks and a simultaneous deposition of carbon in the flat cementite lamella.

The fracture of lamellae (cf. Fig. 2(b), single arrow) in the pearlite colonies with lamellae oriented perpendicular to the rolling direction can also accelerate the spheroidization. Fragments of the former lamellae located at a prior austenite grain boundary (cf. Fig. 2(b), double arrow) can easily be formed because of an accelerated diffusion along the boundary, which leads to a faster coarsening of these cementite fragments.

For the case of a heavy deformation the substructure of the pearlite lamellae can also exhibit an essential effect on the spheroidization process. As reported in [7], the interface adjacent to the subboundary in the cementite lamella with a large local curvature and the surrounding ferrite provokes a quick carbon dissolution that leads to a local lamella division (double arrow in Fig. 2(c)).

The start of the spheroidization of the cementite lamellae in the vicinity of ferrite subboundaries, as reported in [8], was also observed (cf. Fig. 2(c), single arrow). In this case the subboundary facilitates the deposition of carbon in contact place with the lamella. But 

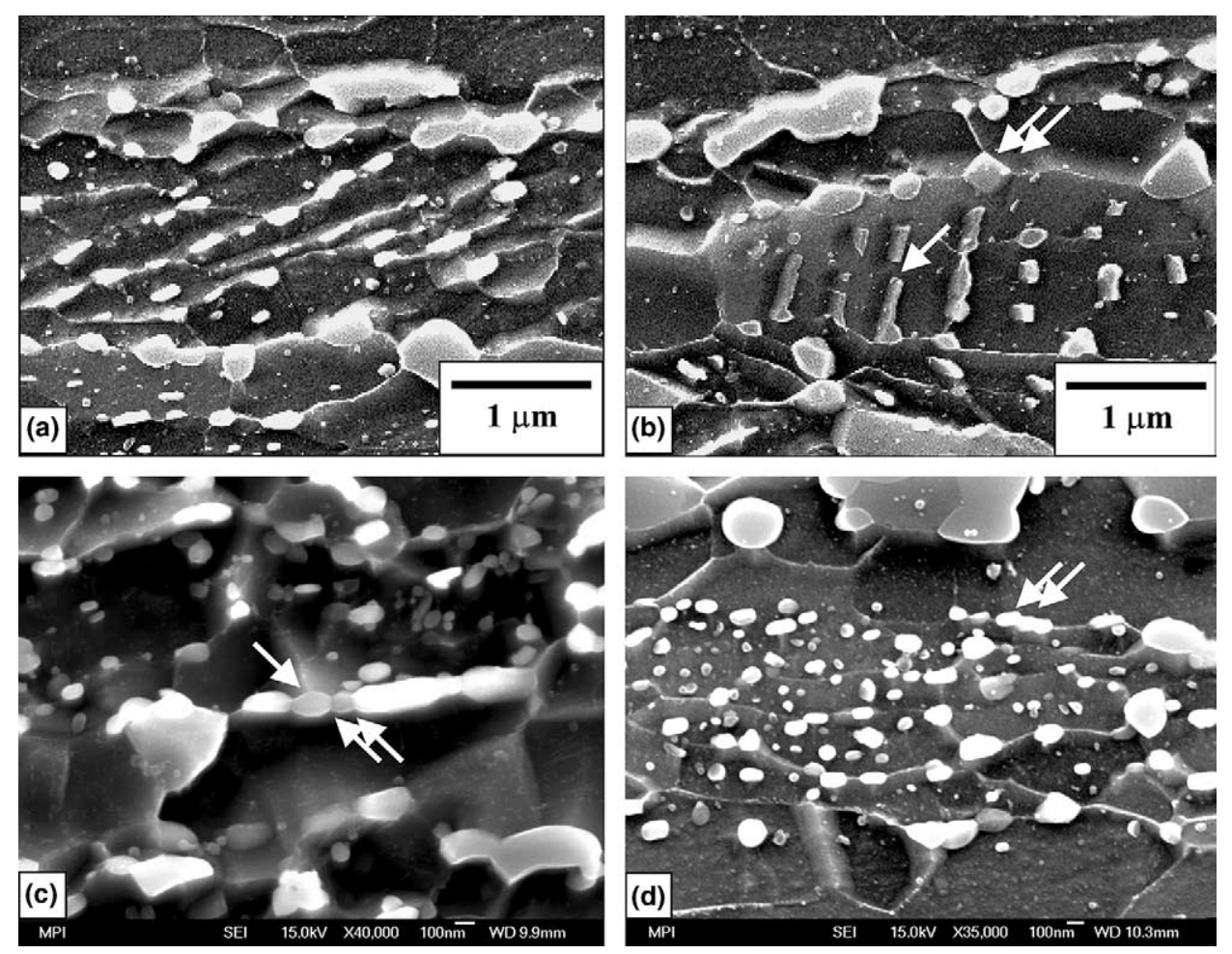

Fig. 2. Spheroidization of pearlite: (a) cementite particles along the former lamellae; (b) fracture of lamellae (single arrow) and the lamella fragments at a prior austenite grain boundary (double arrow); (c) enhancing effect of ferrite boundary (single arrow) and cementite subboundaries (double arrow) on start of spheroidization and (d) former pearlite colony (double arrow shows the spheroidization of kinked lamella).

this mechanism does not seem to have a first-order effect for a heavily warm deformed steel. The present EBSD study has shown that the processes of spheroidization and redistribution of cementite take place already in a deformed ferrite, when subboundaries do not yet exist.

The appearance of a typical former pearlite colony at the end of the spheroidization process is shown in Fig. 2(d). Along the former lamellae the ferrite boundaries with the cementite chains can be seen. The ferrite between the chains is elongated and seems to be deformed. Some cementite particles have a prolonged form. The spheroidization of the last kinked lamella can be also observed (cf. Fig. 2(d), double arrow).

\subsection{Distribution of cementite}

Apart from the processes of spheroidization and coarsening of cementite, which are typical for eutectoid steels [1], the process of a homogeneous distribution of cementite after the spheroidization in the present ferritic-pearlitic steel have been observed. This means that after HWD with a subsequent coiling even within the former proeutectoid ferrite regions cementite particles can also be found. The various stages of the cementite redistribution after a cooling rate of $10 \mathrm{~K} / \mathrm{s}$ and deformation/coiling temperatures 873-943 K $\left(600-670{ }^{\circ} \mathrm{C}\right)$ are shown in Fig. 3. At an early stage of the redistribution process, accomplished here by using a rather low deformation/coiling temperature of $873 \mathrm{~K}\left(600{ }^{\circ} \mathrm{C}\right)$ (cf. Fig. 3(a)), the microstructure contains proeutectoid ferrite without cementite particles and fine spheroidized cementite particles (with a size of about $0.1 \mu \mathrm{m}$ ) that are located at the areas of former pearlite colonies. So, after a complete spheroidization the distribution of cementite is not homogeneous. However, during the deformation/ coiling at higher temperatures, the fine cementite particles may dissolve and some carbon atoms are assumed to diffuse from the areas of the former pearlite colonies to the cementite free areas of the former proeutectoid ferrite followed by a subsequent reprecipitation and coarsening (cf. Fig. 3(b) and (c)). As a result (cf. Fig. 3(d)) the cementite particles with a size of about $1 \mu \mathrm{m}$ are distributed rather homogeneously in the ferritic matrix.

As reported in $[9,10]$, the phenomenon of pearlitecolony dissolution during the annealing of a low carbon titanium microalloyed steel after cold rolling [9] and low carbon vanadium microalloyed steel after severe plastic deformation [10] was observed. In these cases the microalloying elements cause an increase in the recrystallization temperature. The main condition for the redistribution of cementite, as shown in [10], seems to be a high dislocation density in the heavily deformed former pearlite colonies that was estimated to be of the order of $10^{16} \mathrm{~m}^{-2}$. In case of plain low carbon steel $[9,10]$ with low recrystallization temperature, these 

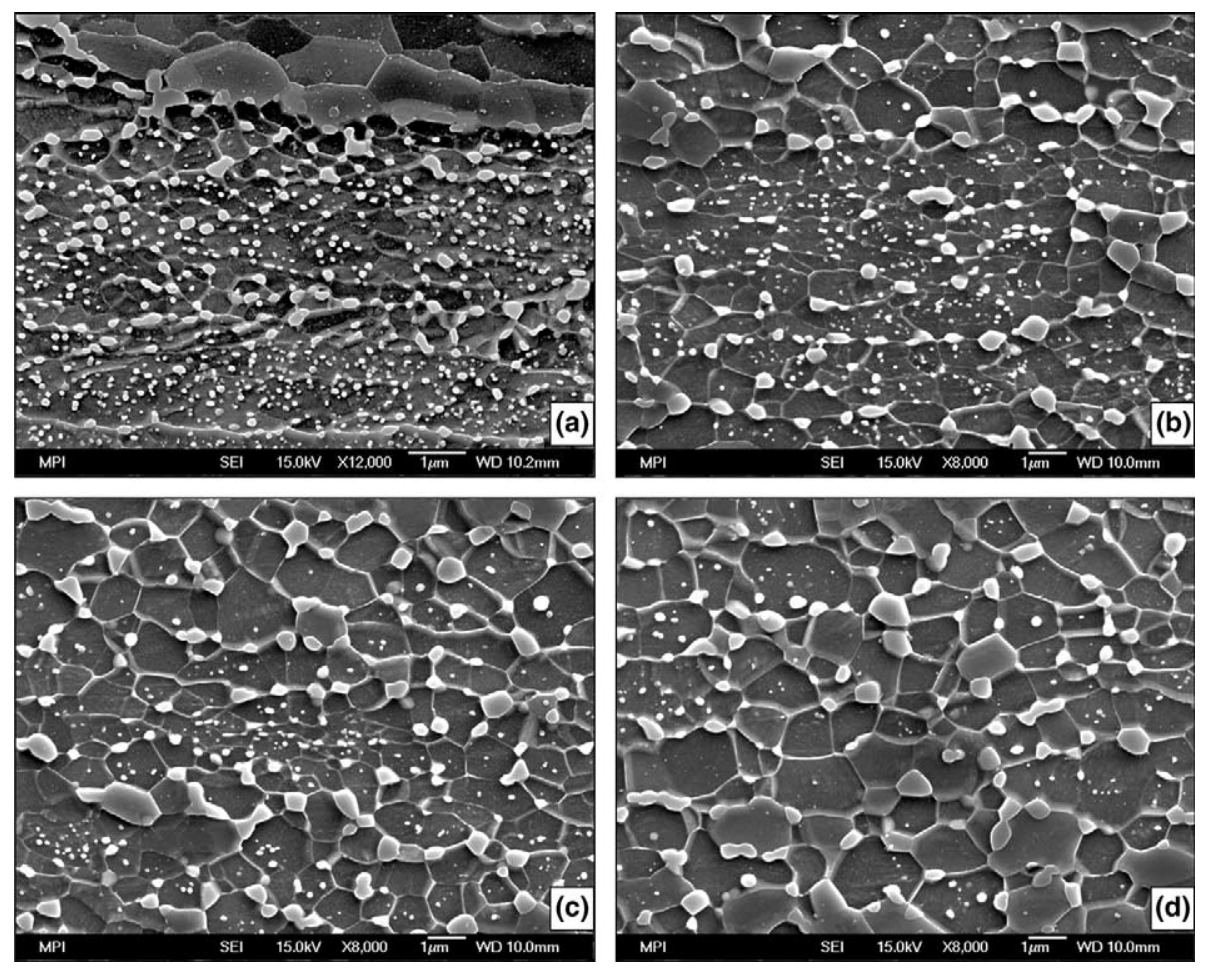

Fig. 3. Effect of deformation/coiling temperature on cementite distribution after cooling rate $10 \mathrm{~K} / \mathrm{s}$ : (a) $873 \mathrm{~K}\left(600{ }^{\circ} \mathrm{C}\right)$; (b) $923 \mathrm{~K}\left(650{ }^{\circ} \mathrm{C}\right)$ and (c,d) $943 \mathrm{~K}\left(670^{\circ} \mathrm{C}\right)$.

treatments did not lead to the disappearance of pearlite colonies. In this steel a recrystallization would slow down or even stop this process by significantly reducing the dislocation density. This means that a higher recrystallization temperature offers the possibility that even at fairly high temperatures, when the cementite dissolution already starts, only recovery takes place. In this situation the dislocation density will not be reduced very much, so that the redistribution of cementite can take place rapidly assisted by a fast dislocation pipe diffusion. On the other hand, in the case of a low recrystallization temperature the recrystallization begins before the start of cementite dissolution, the dislocation density decreases drastically and a decomposition of colonies does not take place.

A driving force for the redistribution can be a gradient of the solute carbon. Inside the former colony around the fine cementite particles the carbon concentration is essentially higher compared to the proeutectoid ferrite. The high density of dislocations and vacancies during or after HWD facilitates the solute carbon diffusion to areas of lower carbon concentration, i.e., proeutectoid ferrite, with subsequent reprecipitation in the most energetically favorable places such as triple joints of ferrite grain boundaries (cf. Fig. 3(d)). Additionally, due to the faster grain boundary diffusion, the particles located on grain boundaries and triple junctions will have a size advantage in the later Ostwaldripening process.

\subsection{Softening of ferrite}

The various stages of ferrite softening after a cooling rate of $10 \mathrm{~K} / \mathrm{s}$ and deformation/coiling temperatures in the range of $903-983 \mathrm{~K}\left(630-710^{\circ} \mathrm{C}\right)$ are shown in Fig. 4(a). After deformation at $903 \mathrm{~K}\left(630^{\circ} \mathrm{C}\right)$ and coiling at the same temperature, the formation of numerous subgrains with low angle boundaries can be observed. These subgrains remain inside the original deformed grains without growth into neighboring grains. Considering only the high angle grain boundaries, it is obvious that the grains are highly elongated in the rolling direction. The amount of high angle grain boundaries (with misorientation angle $>15^{\circ}$ ) is about $50 \%$. After the increase of the deformation/coiling temperature up to $983 \mathrm{~K}\left(710^{\circ} \mathrm{C}\right)$, the fraction of high angle grain boundaries increases up to $65-70 \%$, and the microstructure contains fine equiaxed ferrite grains. However, it seems that most of these grains keep the original orientations of the former deformed grains. For example, the areas with the orientation near $\{111\}$ (cf. Fig. 4(a), single arrow) or near $\{001\}$ (cf. Fig. 4(a), double arrow) consist of fine subgrains with low angle boundaries, which are characteristic for the microstructure up to the highest studied subcritical temperature $983 \mathrm{~K}\left(710^{\circ} \mathrm{C}\right)$.

The ODF sections in Fig. 4(b) show that the texture of the steel essentially does not change after the various deformation/coiling temperatures, containing mainly $\gamma$ 


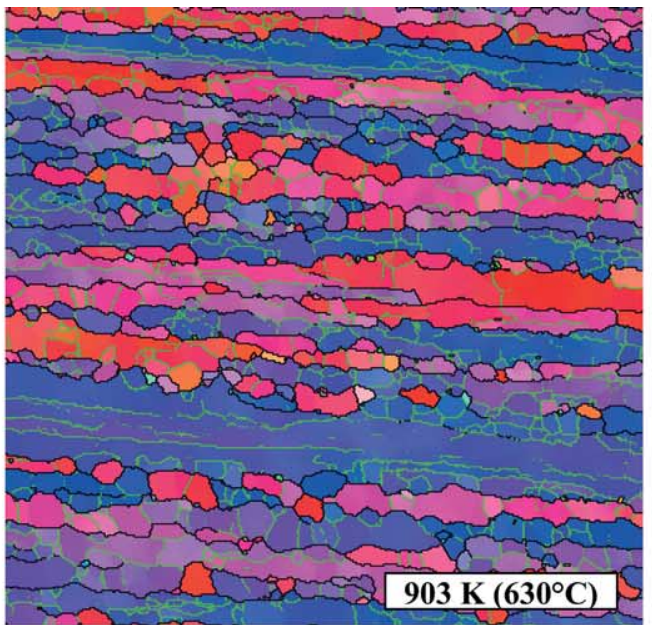

$7.00 \mu$ Boundary levels: $1.5^{\circ} 15^{\circ}$

$7.00 \mu \mathrm{m}=70$ steps $\operatorname{IPF}[001]$

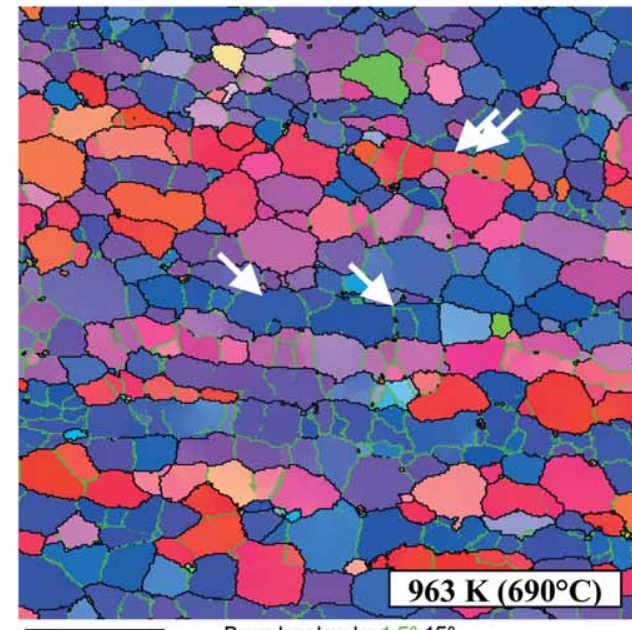

(a)

$7.00 \mu \mathrm{m}=70$ steps $\quad$ IPF [001]

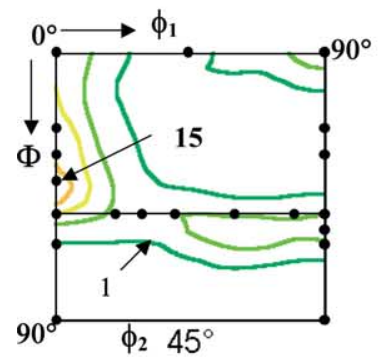

(b) $903 \mathrm{~K}\left(630^{\circ} \mathrm{C}\right)$

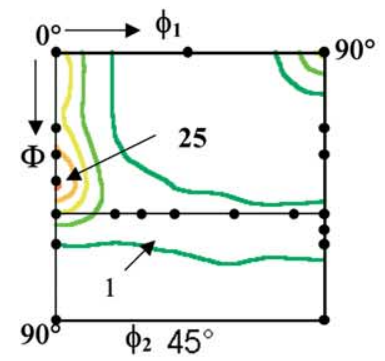

$923 \mathrm{~K}\left(650^{\circ} \mathrm{C}\right)$

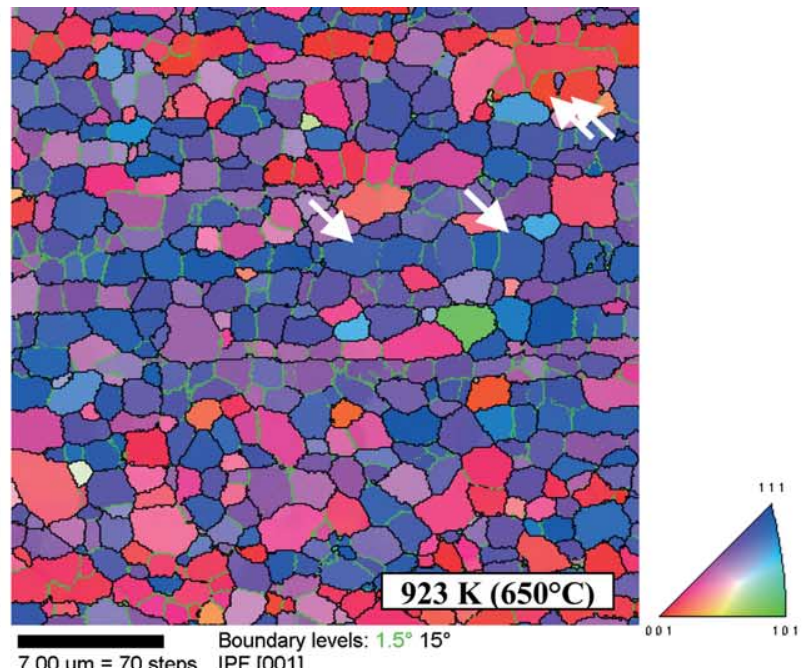

$7.00 \mu \mathrm{m}=70$ steps IPF [001]

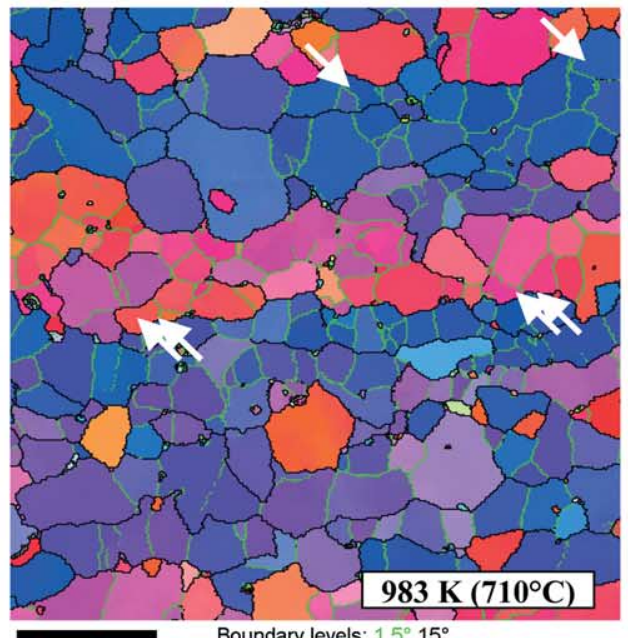

$7.00 \mu \mathrm{m}=70$ steps $\quad$ IPF [001]

Fig. 4. EBSD images (a) and ODF section $\phi_{2}=45^{\circ}$ (b) after the various deformation/coiling temperatures.

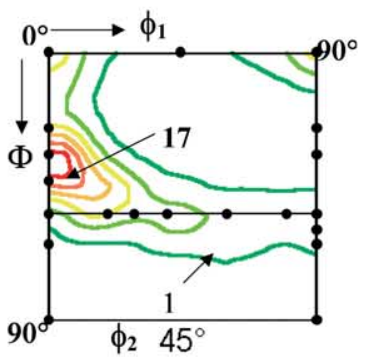

$963 \mathrm{~K}\left(690^{\circ} \mathrm{C}\right)$

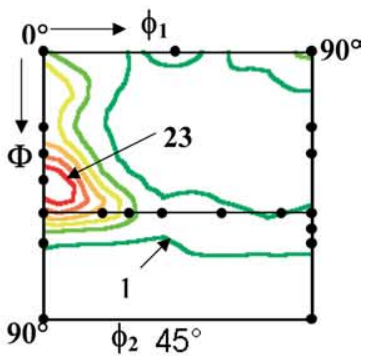

$983 \mathrm{~K}\left(710^{\circ} \mathrm{C}\right)$ and $\alpha$-fibers with a maximum near $\left\{\begin{array}{llll}1 & 1 & 2\end{array}\right\}\left\langle\begin{array}{llll}1 & 1 & 0\rangle & \text {, which }\end{array}\right.$ is typical for rolling texture $[11,12]$.

The distribution of grain/subgrain boundaries misorientations (Fig. 5) for the deformation/coiling temperatures $903 \mathrm{~K}\left(630^{\circ} \mathrm{C}\right)$ and $983 \mathrm{~K}\left(710^{\circ} \mathrm{C}\right)$ are very similar. They both show a high fraction of low angle grain boundaries with small misorientation angles. The increase of the temperature by $80 \mathrm{~K}$ leads only to a continual decrease of the low angle fraction $\left(<15^{\circ}\right)$ with a simultaneous increase of the fraction of high angle boundaries. (Because of the orientation noise in the EBSD measurements misorientations less than $1.5^{\circ}$ have been omitted).

The distribution of the ferrite grain size (Fig. 6) shows also a continuous change of the microstructure with increasing HWD temperature. After the temperature $630{ }^{\circ} \mathrm{C}(903 \mathrm{~K})$, the absolute maximum of the area fraction corresponds to the grain size of around $2 \mu \mathrm{m}$. A 


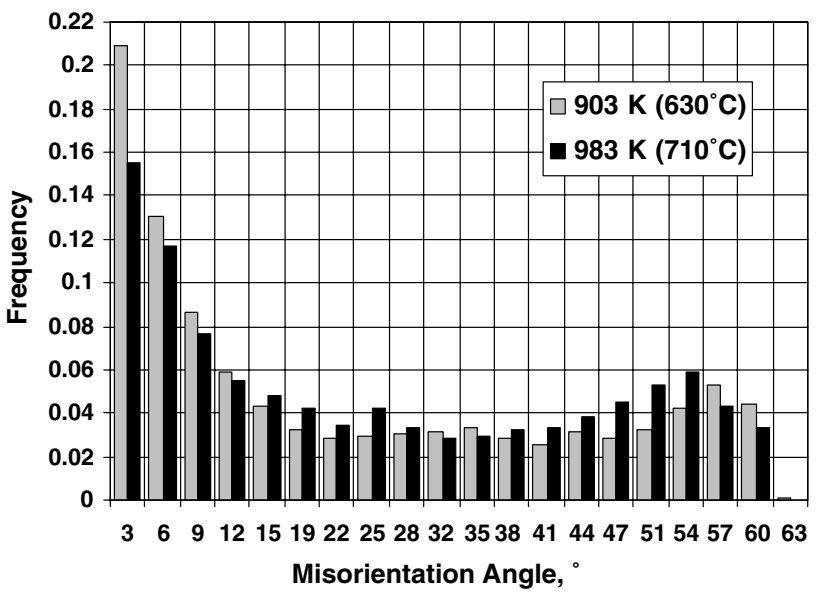

Fig. 5. Distribution of grain/subgrain boundaries misorientations.

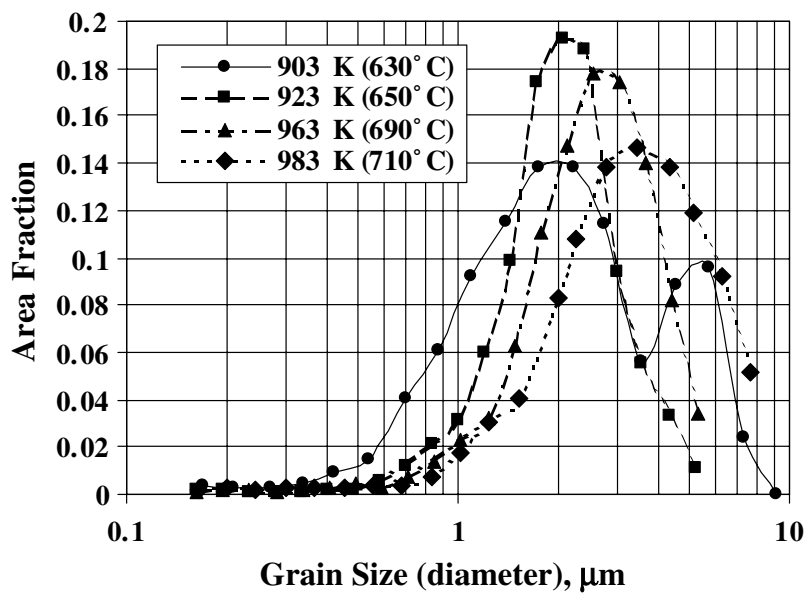

Fig. 6. Area fraction of ferrite grain size after the various deformation / coiling temperatures.

further local maximum near $6 \mu \mathrm{m}$ can be attributed to the large deformed ferrite grains still without substructure. After the deformation/coiling at $923 \mathrm{~K}$, the curve exhibits a fairly sharp maximum for grain sizes around $2.2 \mu \mathrm{m}$. The further increase of the temperature leads to a shift of the maximum area fraction to larger grain sizes up to $3.5 \mu \mathrm{m}$ for $983 \mathrm{~K}$.

Thus, the results of the study suggest that the ferrite softening during the deformation with the subsequent coiling can be attributed to recovery processes (i.e., polygonization), called also continuous recrystallization or recrystallization in situ. In this case the subgrains form within the deformed matrix and grow, so that the dislocation density decreases due to the reduction of subgrain boundaries area and, finally, formation of high angle grain boundaries.

The reasons that only recovery and not primary recrystallization takes place here may be described as follows. Due to the lamellae spheroidization, a fine dispersion of cementite particles are present in the microstructure. These particles lead to a high dragging force for the migration of high angle grain boundaries due to Zener pinning of the boundaries that increases the recrystallization temperature. On the other hand, it is known that due to high stacking fault energy the recovery in ferrite can proceed very quickly. In this case the dislocation-rearrangement to form energetically more favorable configurations starts everywhere, but the subsequent migration of high angle grain boundaries may be stopped very soon by the particles.

The recovery process decreases both the stored energy and the local stored energy gradient, which slows down the successful nucleation or growth. Moreover, an increased amount of solute carbon in ferrite during the HWD and the redistribution of cementite due to the spheroidization process can retard both the formation and migration of high angle boundaries.

At higher temperatures, the homogeneously distributed relatively fine cementite particles produce a stabilizing effect on the fine grained ferrite matrix. But the coarsening of the cementite particles leads to a reduction of the Zener drag effect, so that primary recrystallization and grain growth can occur.

Because the recovery processes involve a short-range interaction between dislocations and subgrain boundaries, or between adjacent boundaries, they may lead to a sharpening of deformation texture and a higher intensity of deformation texture components, which can be seen in Fig. 4(b).

The start of the formation of low angle subgrain boundaries due to dislocation rearrangement in a deformed grain is shown in Fig. 7(a) (EBSD image and misorientation profile). The initial deformed grain with the main orientation component near $\{111\}$, with a length of more than $10 \mu \mathrm{m}$ and a width in normal direction of $1-1.5 \mu \mathrm{m}$ contained initially (after the deformation) a high density of excess dislocations, which resulted in a fairly high long-distance misorientation gradient $\sim 0.5-1 \% \mu \mathrm{m}$ along the rolling direction. The climb and cross slip of dislocations lead to their rearrangement as low angle boundaries. The misorientation profiles allow observation the beginning of subgrain formation. The plateaus at the "point-to-origin" profile evidently can be attributed to new subgrains with low angle boundaries near $1^{\circ}$, as shown in the "pointto-point" profile.

The formation of low angle subboundaries in progress is shown in Fig. 7(b). In the initial deformed grain with an orientation component near $\left\{\begin{array}{lll}1 & 2\end{array}\right\}$, the low angle boundaries between new subgrains already have higher misorientation angles up to $9^{\circ}$, with a subgrain size of about $1-3 \mu \mathrm{m}$.

An increase in temperature leads to the continuous decrease of the fraction of low angle boundaries along with a simultaneous increase of high angle ones (cf. Fig. 5). As a result, the amount of high angle boundaries 


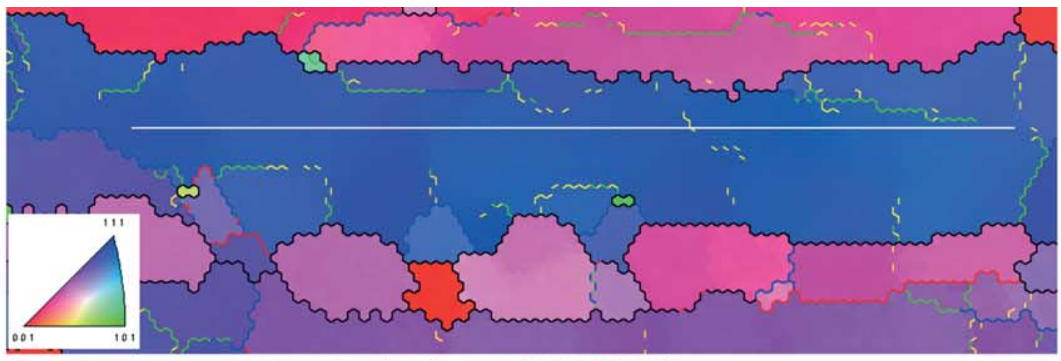

(a)

$$
2.00 \mu \mathrm{m}=20 \text { steps IPF [001] }
$$

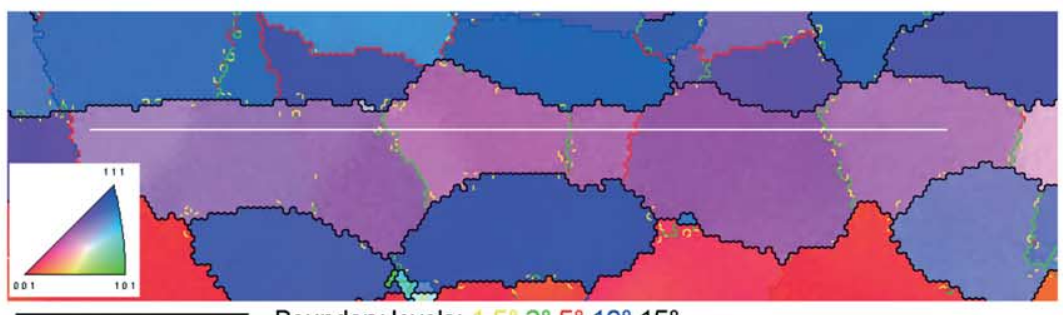

(b) $3.50 \mu \mathrm{m}=35$ steps IPF [001]

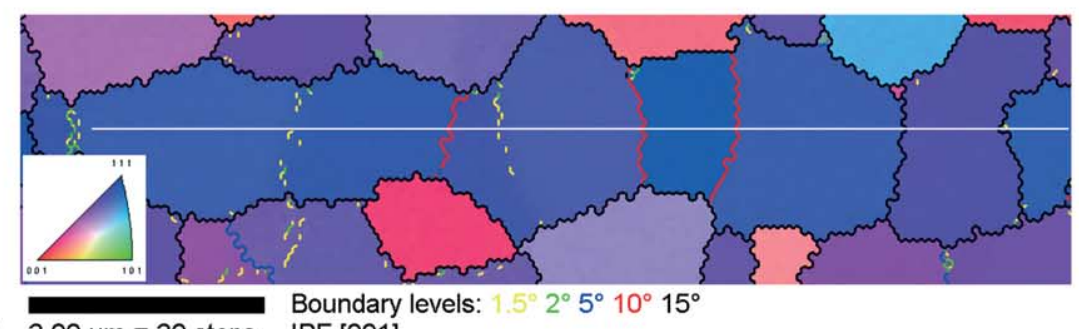

(c) $3.00 \mu \mathrm{m}=30$ steps IPF [001]

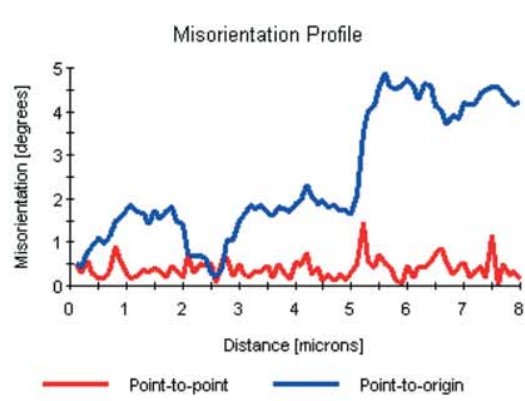

Misorientation Profile

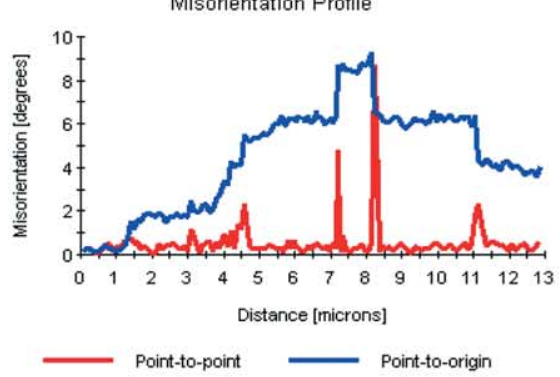

Misorientation Profile

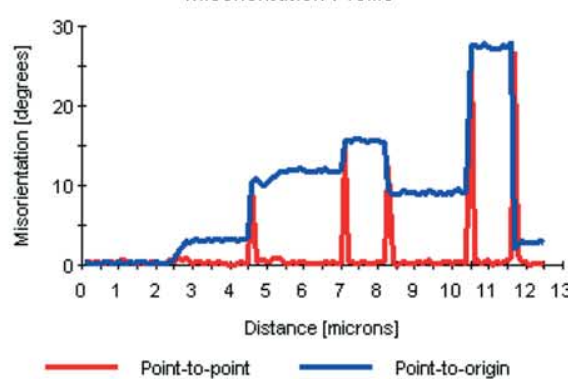

Fig. 7. Formation of (sub)grain boundaries during continuous recrystallization: (a) start of low angle subgrain boundaries formation; (b) formation of low angle subgrain boundaries in progress and (c) formation of high angle grain boundaries due to dislocation accumulation on low angle boundaries.

increases up to $\sim 70 \%$. As shown in literature, the continuous recrystallization clearly contributes to the formation of new high angle boundaries. The possible mechanisms are the accumulation of dislocations at the subgrain boundaries [13], the increase of misorientation angle by the merging of lower angle boundaries during subgrain coalescence $[14,15]$ and the subgrain growth with migration of low angle boundaries via dislocation motion [16]. In the postmortem analysis carried out in this work it is not possible to prove exactly, which mechanism is really active or relevant for the microstructure development. Nevertheless, some of the interesting features found in the microstructures will be discussed to illustrate the possible mechanisms of continuous recrystallization in studied steel.

The increase of boundary misorientation that can be attributed to the accumulation of dislocations into subboundaries is shown in Fig. 7(c). A strained grain is separated into several subgrains of similar orientation around $\left\{\begin{array}{lll}1 & 1 & 1\end{array}\right\}$. One of these (sub)grains already exhibits misorientations of up to $25^{\circ}$ to the neighboring (sub)grain.

Subgrain coalescence is often reported to be a very slow process. Nevertheless, the microstructure in Fig. 8(a) might be contributed by the coalescence of two subgrains with orientation near $\left\{\begin{array}{lll}1 & 1 & 1\end{array}\right\}$ and misorientation $\leqslant 1^{\circ}$ (see misorientation profile, Fig. 8(b)). As reported in [17], the coalescence can be favorable in case of joining subgrains surrounded by high angle boundaries. This condition is completely fulfilled for subgrains A1 and A2, which are surrounded by high angle boundaries ranging from $20^{\circ}$ up to $47^{\circ}$. Preferential subgrain coalescence may occur since the driving force for subgrain merging comes from the difference between the higher energy of dislocations in the low angle boundary and the lower energy of the dislocations in the high angle boundaries. Since the high angle boundaries around two subgrains with low misorientation do not occur often, the coalescence of subgrains is observed 

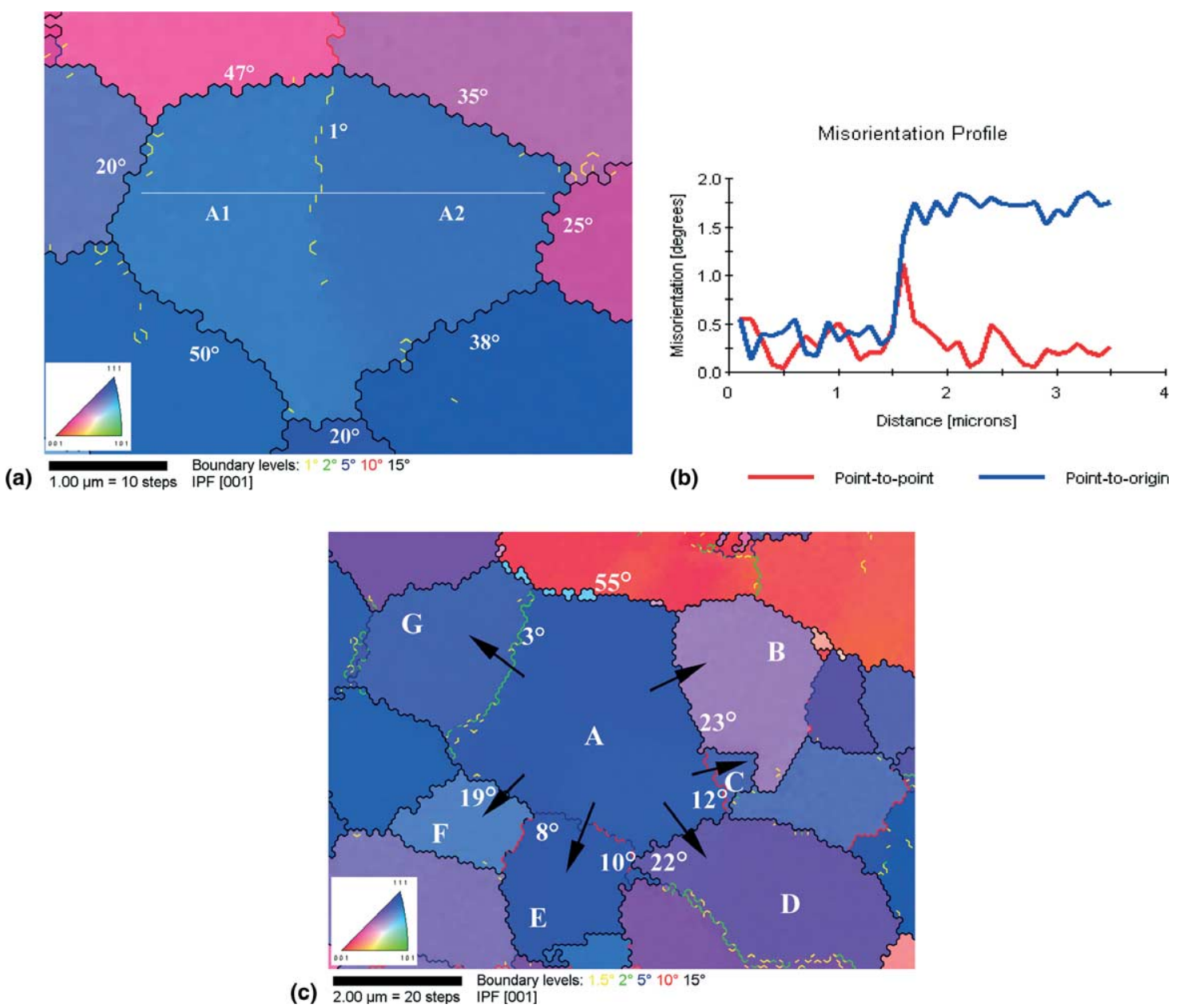

Fig. 8. The processes of two subgrains coalescence: (a) EBSD image, (b) misorientation profile and (c) subgrain growth (EBSD image); the misorientation angles between grains are shown.

only rarely, compared to other mechanisms of continuous recrystallization.

The possible subgrain growth is shown in Fig. 8(c). The curvature of the boundaries indicates the growth of the subgrain A with orientation near $\{111\}$ at the expense of the adjacent (sub)grains (see arrows). Apart from the high angle boundaries migration (between grain $\mathrm{A}$ and the each of grains $\mathrm{B}, \mathrm{D}$ and $\mathrm{F}$, the boundaries have misorientations of about $20^{\circ}$ ), the migration of low angle boundaries can be observed (AC $12^{\circ}$, AE near $9^{\circ}$ and the boundary between $A$ and $G$ has a misorientation angle only about $3^{\circ}$ ).

As reported in [18], low angle boundaries in general have a low mobility. The reason is the different structure of high and low angle boundaries. For high angle boundaries, migration can occur easily by single atom jumps across the rather open grain boundary structure. Low angle boundaries composed of dislocation arrays migrate by the motion of dislocations, i.e., a coordinated movement of atoms. While the motion of an individual dislocation by glide is easy, the motion of an array might be more difficult, since motion of the arrays causes a change in shape of the two subgrains, which is resisted by surrounding subgrains. As reported in [18], the limitative process of the array motion is the climb of edge dislocations and the activation energy of the process has the order of magnitude of the activation energy for selfdiffusion. On the other hand, as shown in [19], even a rather low deformation leads to a decrease of the selfdiffusion activation energy.

The activation energy of the (sub)grain growth with the increase of the deformation/coiling temperature was estimated using the (sub)grain size with the maximum area fraction (cf. Fig. 6).

The estimation was carried out based on the following considerations. As shown in [18], for isothermal annealing a time law of the form

$d=(a t)^{n}$

is frequently found, where $d$ is grain size, $t$ is time, and $n$ and $a$ are constants. As reported in [20,21], $n \leqslant 0.5$, in [19] $n=0.5$. 
As shown in $[19,21]$ the increase in temperature leads to the exponential increase of constant $a$ that has the nature of a diffusion coefficient [19]

$a=a_{0} \exp (-Q / R T)$,

where $Q$ is the activation energy of grain growth, $T$ is the absolute temperature and $a_{0}$ is constant. For isochronous conditions

$d=a_{0}^{n} \exp (-n Q / R T)$

and a plot of $\ln d$ versus $1 / T$ allows for determining the activation energy $Q$ of grain growth from the gradient $(-n Q / R T)$.

The plot of $\ln d$ versus $1 / T$ is shown in Fig. 9. It can be seen that for temperatures $903-963 \mathrm{~K}\left(630-690{ }^{\circ} \mathrm{C}\right)$, the process has a lower activation energy compared to the grain growth in a range $963-983 \mathrm{~K}\left(690-710^{\circ} \mathrm{C}\right)$. Here, it should be mentioned that the point for $903 \mathrm{~K}\left(630^{\circ} \mathrm{C}\right)$, where the process of subgrain formation only starts, apparently can be assigned to the line 923-963 K (650 $690{ }^{\circ} \mathrm{C}$ ), where the process is in progress. Assuming that $n=0.5$, the activation energies at lower and higher temperature ranges can be calculated as 71 and $205 \mathrm{~kJ} /$ mol, respectively. According to Kristal [19], the lower $Q$ can be attributed to the activation energy of interstitial elements diffusion (carbon or nitrogen), the higher $Q$ has the order of magnitude of the self-diffusion activation energy of deformed ferrite. This might mean that the limiting factor of ferrite softening at the temperatures up to $963 \mathrm{~K}\left(690{ }^{\circ} \mathrm{C}\right)$ is carbon diffusion during the spheroidization and distribution of cementite.

\subsection{Effect of cementite on ferrite softening}

Just after the spheroidization (cf. Fig. 3) the size of cementite particles can be about $0.1 \mu \mathrm{m}$. The presence of these fine cementite particles retards the softening of ferrite in the areas of the former pearlite colonies. The microstructure of steel with fine cementite is shown in

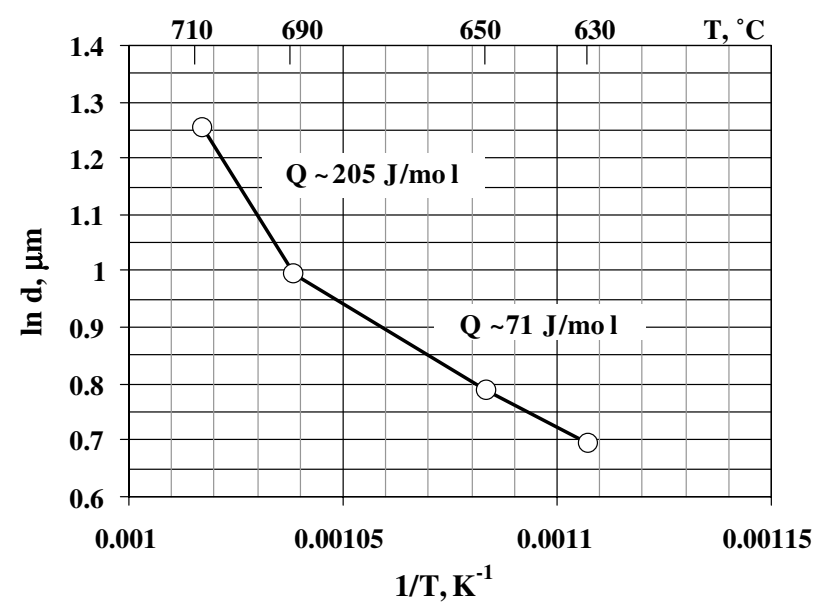

Fig. 9. Different stages of ferrite grain growth.

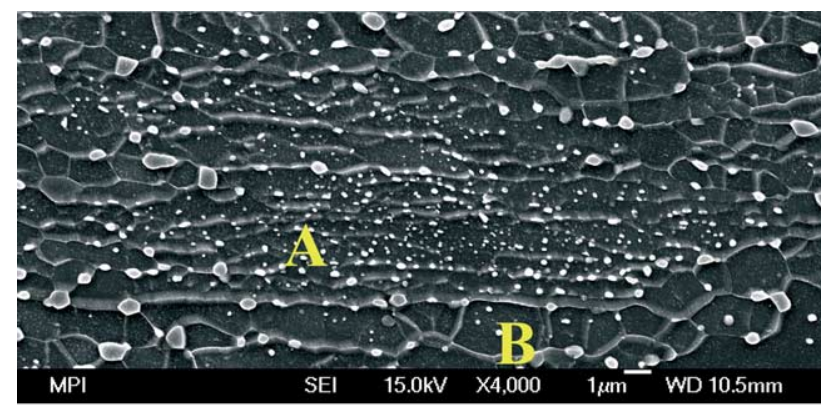

(a)

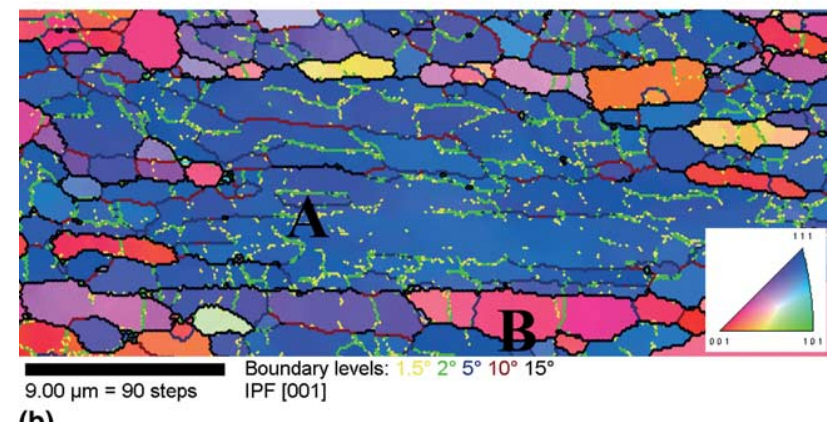

(b)

Fig. 10. Effect of cementite on ferrite softening process: (a) SEM and (b) EBSD image.

SEM and EBSD images of the same location in Fig. 10. It can be seen that in the area of fine cementite the formation of subgrains is not complete (cf. Fig. 10, area A). On the contrary, in the area of proeutectoid ferrite, the rearrangement of dislocations with the formation of low angle subgrain boundaries is in progress (cf. Fig. 10, area B).

This confirms that the limitation factor of ferrite softening can be the diffusion of carbon atoms. As shown in [15], for two-phase alloys the decomposition before recrystallization is controlled by the lower activation energy for diffusion of interstitial atoms (carbon) as compared to that which controls primary recrystallization (self-diffusion of iron atoms). The processes of spheroidization and distribution of cementite might be assumed to be decomposition, since they can be attributed to a local change of chemical composition, i.e., the change of carbon content in solid solution during lamellae dissolution, cementite re-precipitation, as well as dissolution of the fine particles with a coarsening of larger ones. Obviously, the formation and growth of ferrite subgrains are controlled by solute carbon and cementite particles, which grow by diffusion of carbon. The particle spacing determines the size of subgrains.

\subsection{Effect of initial microstructure on cementite distribu- tion and ferrite softening}

As shown in Fig. 1, various cooling rates allow for obtaining various initial microstructures before the HWD. The effect of the cooling rate, i.e., the initial microstructure on the microstructure after HWD was studied. 
The microstructures after HWD of steels with two different cooling rates and deformation/coiling temperatures $10 \mathrm{~K} / \mathrm{s}, 943 \mathrm{~K}\left(670{ }^{\circ} \mathrm{C}\right)$ and $20 \mathrm{~K} / \mathrm{s}, 973 \mathrm{~K}(700$ ${ }^{\circ} \mathrm{C}$ ) are shown in Fig. 11. In the case of low cooling rate $(10 \mathrm{~K} / \mathrm{s})$, the microstructure after transformation is composed of proeutectoid ferrite and pearlite. With this initial microstructure, the HWD and subsequent simulated coiling (cf. Fig. 11(a)) results in a homogeneous distribution of cementite particles in a fine grained ferrite matrix, according to processes, shown and discussed earlier. According to the EBSD measurement, the ferrite contains about $65 \%$ high angle grain boundaries indicating advanced progress of continuous recrystallization. The increase of the cooling rate up to $20 \mathrm{~K} / \mathrm{s}$ leads to a microstructure with proeutectoid ferrite, a finer pearlite and bainite, which results in areas with accentual finer cementite particles after HWD even at higher deformation/coiling temperature of $973 \mathrm{~K}\left(700{ }^{\circ} \mathrm{C}\right)$. These very fine cementite particles retard a subgrain formation in these areas (cf. Fig. 10). As a result the final microstructure is inhomogeneous and contains only $45 \%$ high angle ferrite grain boundaries (cf. Fig. 11(b)).

\subsection{Coarsening of ferrite}

The microstructure with fine ferrite (sub)grains that is stabilized due to homogeneously distributed cementite particles is fairly stable even after the deformation/ coiling at high temperatures of ferritic range. But by some unfavorable circumstances some enlarged subgrains can abnormally grow.

Such a situation can occur in an inhomogeneous initial microstructure after a higher cooling rate near 20 K/s (cf. Fig. 11(b)). In this case, a local stored energy gradient may facilitate the preferential growth of one or several grains with high angle boundaries, as shown in Fig. 12. The grains in the areas of the former proeutectoid ferrite (cf. Fig. 10, area B), with coarser cementite particles, can be such potential fast growing grains. This abnormal grain growth is enhanced if the growing grain is surrounded by areas with essential higher stored energy, i.e., subgrains with low angle boundaries and partly deformed grains. The energy lowering due to the consumption of these areas by the growing coarse grain provides the driving force for this process.
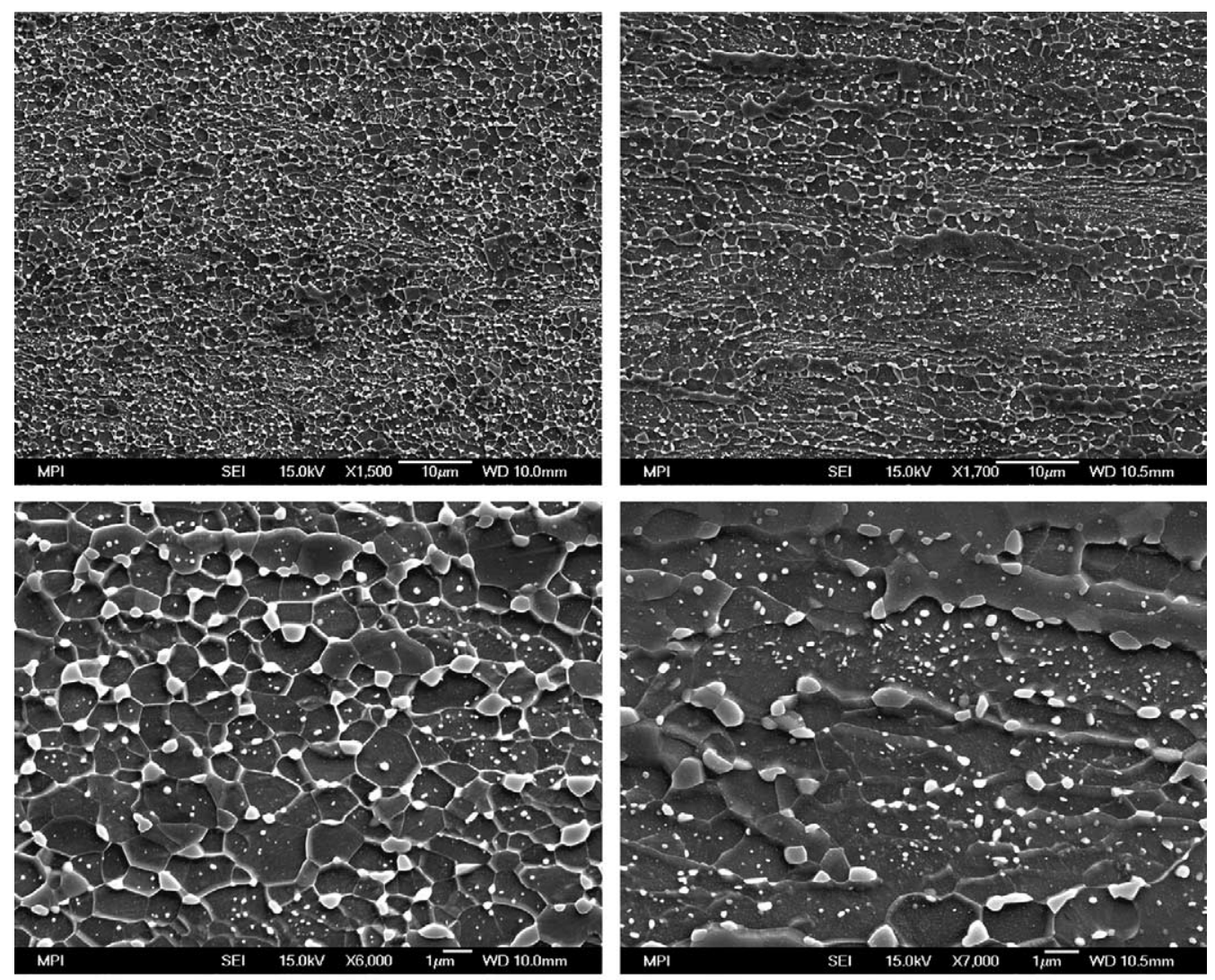

(a)

(b)

Fig. 11. Microstructure after the various cooling rates and deformation/coiling temperatures: (a) $10 \mathrm{~K} / \mathrm{s}$, $943 \mathrm{~K}\left(670{ }^{\circ} \mathrm{C}\right)$ and (b) $20 \mathrm{~K} / \mathrm{s}$, $973 \mathrm{~K}$ $\left(700{ }^{\circ} \mathrm{C}\right)$. 


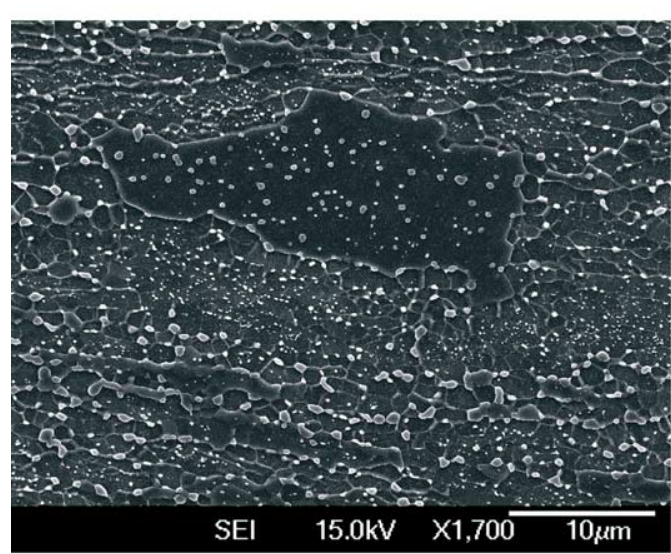

(a)

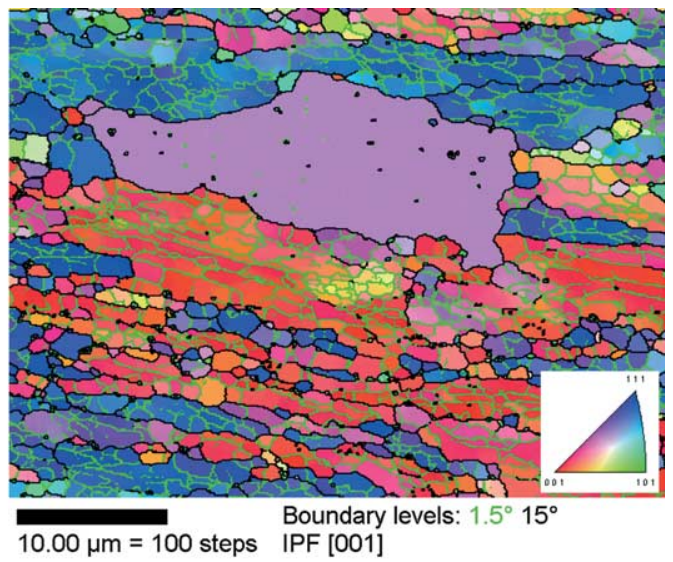

(b)

Fig. 12. Coarsening of ferrite: (a) SEM and (b) EBSD image.

\section{Conclusions}

1. Spheroidization of pearlite during the HWD is accelerated by the formation of cementite lamellae kinks, fracture of lamellae and cementite subboundaries. Higher equilibrium carbon concentration in ferrite (higher carbon solubility) near these lamellae defects provokes a quick local dissolution of the lamella that leads to its division with a subsequent or simultaneous spheroidization.

2. A rather homogeneous distribution of cementite in an initially ferritic-pearlitic microstructure can be observed due to increase of deformation/coiling temperatures to $943-973 \mathrm{~K}\left(670-700{ }^{\circ} \mathrm{C}\right)$. This process is assumed to proceed by the local partial dissolution of former pearlite colonies due to a local increase of carbon solubility in ferrite. Simultaneously, the solute carbon may diffuse into the cementite-free proeutectoid ferrite areas with lower equilibrium carbon concentration and re-precipitate. Both of these processes are supported by a high density of lattice defects due to HWD.

3. Ferrite softening during the HWD can be attributed to a continuous or in situ recrystallization. Primary recrystallization is hardly probable because of the relatively low stored energy at rather high deformation temperatures as well as an increased amount of solute carbon in ferrite during the cementite spheroidization and fine cementite particles produced by spheroidization.

4. Continuous recrystallization contributes to high angle boundaries development due to accumulation of dislocations at the subgrain boundaries, by the subgrain growth with migration of low angle boundaries and by the merging of lower angle boundaries during subgrain coalescence.

5. According to the determination of activation energy of (sub)grain growth, the controlling factor of ferrite softening in the temperature range 903-963 K (630- $690^{\circ} \mathrm{C}$ ) is carbon diffusion during the spheroidization and redistribution of cementite.

6. The HWD of steel with initial ferrite-pearlite microstructure (after cooling rate $10 \mathrm{~K} / \mathrm{s}$ ) results in a homogeneous distribution of cementite in a fine grained ferrite matrix with about $65-70 \%$ high angle grain boundaries. On the contrary, the HWD of steel with initial ferritepearlite-bainite microstructure (after cooling rate 20 $\mathrm{K} / \mathrm{s}$ ) brings about an inhomogeneous cementite distribution with the areas of fine cementite particles and only $45 \%$ high angle ferrite grain boundaries.

7. In case of inhomogeneous microstructure (cooling rate $20 \mathrm{~K} / \mathrm{s}$ ), a high local gradient in the size of cementite particles tends to facilitate the preferential growth of some grains with mobile high angle boundaries, which leads to microstructure coarsening.

\section{Acknowledgements}

The authors express their gratitude to the financial support of the European Coal and Steel Community (ECSC).

\section{References}

[1] Kaspar R, Kapellner W, Lang C. Steel Res 1988;59(11):492.

[2] Robbins J, Shepard O, Sherby O. J Iron Steel Inst 1964;202(Oct.):804.

[3] Pawelski O, Kaspar R. Materialprüfung 1988;30(11-12):357.

[4] Chattopadhyay S, Sellars S. Acta Met 1982;30(1):157.

[5] Watanabe T, Karashima S. Physica Status Solidi 1970;42:749.

[6] Chalmers B. Physical metallurgy. New York: Wiley; 1959.

[7] Novikov I. Theory of heat treatment of metals. Moscow: Metallurgia; 1986. p. 479.

[8] Paqueton H, Pineau A. JISI 1971;209(12):991.

[9] Babich V, Nesterenko A, Storojeva L. Met Sci Heat Treat (USSR) 1989;31(9-10):692.

[10] Shin D, Park K, Kim Y. Scripta Mater 2003;48(5):469. 
[11] Hutchinson B, Bate P. In: Proceedings of the International Conference on Properties and Application of IF Steels. Tokyo: ISIJ; 2003. p. 337.

[12] Quadir M, Duggan B. In: Proceedings of the International Conference on Properties and Application of IF Steels. Tokyo: ISIJ; 2003. p. 357.

[13] Hales S, McNelley T, McQueen H. Metall Mater Trans A 1991;22A:1037.

[14] Hornbogen E, Köster U. In: Haessner F, editor. Recrystallization of metallic materials. Berlin: Dr. Riederer Verlag; 1978. p. 159.
[15] Hornbogen E. Metall Mater Trans A 1979;10A:947.

[16] Nes E. In: Baudelet B, Surey M, editors. Superplasticité. Paris: Centre National de la Recherche Scientifique; 1985. p. 7.1.

[17] Doherty R, Cahn R. J Less-Common Metals 1972;28:279.

[18] Haessner F, editor. Recrystallization of metallic materials. Stuttgart: Dr. Riederer Verlag; 1978. p. 293.

[19] Kristal M. Diffusion processes in iron alloys. Moscow; 1963. p. 278.

[20] Holmes E, Winegard W. Acta Met 1959;7:411.

[21] Drolet J, Galibois A. Acta Met 1968;16:1387. 